\title{
Article \\ Biogenic Synthesis of AgNPs Using Aqueous Bark Extract of Aesculus indica for Antioxidant and Antimicrobial Applications
}

\author{
Muhammad Riaz ${ }^{1, *(1)}$, Amrina Suleman ${ }^{2, *}$, Pervaiz Ahmad ${ }^{3}\left(\mathbb{0}\right.$, Mayeen Uddin Khandaker ${ }^{4}$, Amal Alqahtani ${ }^{5, *}(\mathbb{C}$, \\ David A. Bradley ${ }^{4,6}$ and Muhammad Qayyum Khan ${ }^{2}$
}

1 SA-Centre for Interdisciplinary Research in Basic Science (SA-CIRBS), International Islamic University, Islamabad 44000, Pakistan

2 Department of Botany, University of AJK, Muzaffarabad 13100, Pakistan; mqkhan2003@yahoo.com

3 Department of Physics, University of AJK, Muzaffarabad 13100, Pakistan; pervaiz_pas@yahoo.com

4 Centre for Applied Physics and Radiation Technologies, School of Engineering and Technology, Sunway University, Bandar Sunway 47500, Selangor, Malaysia; mayeenk@sunway.edu.my (M.U.K.); d.a.bradley@surrey.ac.uk (D.A.B.)

5 Department of Basic Sciences, Deanship of Preparatory Year and Supporting Studies, Imam Abdulrahman Bin Faisal University, P.O. Box 1982, Dammam 34212, Saudi Arabia

6 Center for Nuclear and Radiation Physics, Department of Physics, University of Surrey, Guilford, Surrey GU2 7XH, UK

* Correspondence: mriaz1786@yahoo.com (M.R.); mriaz@iiu.edu.pk (A.S.); amalqahtani@iau.edu.sa (A.A.)

\section{check for}

updates

Citation: Riaz, M.; Suleman, A.;

Ahmad, P.; Khandaker, M.U.;

Alqahtani, A.; Bradley, D.A.; Khan, M.Q. Biogenic Synthesis of AgNPs Using Aqueous Bark Extract of Aesculus indica for Antioxidant and Antimicrobial Applications. Crystals 2022, 12, 252. https://doi.org/ $10.3390 /$ cryst12020252

Academic Editors: Helmut Cölfen and Jolanta Prywer

Received: 26 November 2021

Accepted: 9 February 2022

Published: 12 February 2022

Publisher's Note: MDPI stays neutral with regard to jurisdictional claims in published maps and institutional affiliations.

Copyright: (c) 2022 by the authors Licensee MDPI, Basel, Switzerland. This article is an open access article distributed under the terms and conditions of the Creative Commons Attribution (CC BY) license (https:// creativecommons.org/licenses/by/ $4.0 /)$.

\begin{abstract}
Nanotechnology has received a lot of attention from the scientific community because of the greater surface-to-volume ratio of nanomaterials, which phenomenally increases their efficacy in practical applications. Among the various synthesis techniques, the biogenic or green synthesis of nanomaterials shows advantages over other techniques such as physical, chemical, etc. This study reports the biogenic synthesis of silver nanoparticles (AgNPs) using aqueous bark extract of Aesculus indica. The as-synthesized NPs were characterized by UV-visible, FT-IR, XRD, and SEM, and then tested for their antioxidant and antimicrobial potency. We have identified phenols, flavonoids, tannins, saponins, and carbohydrates in the bark extract of $A$. indica. The extract-loaded-AgNPs showed the highest inhibition for Staphylococcus aureus $(28.0 \mathrm{~mm})$, Pseudomonas aeruginosa $(17.66 \mathrm{~mm})$, Escherichia coli (14.33 mm), Acetobacter serratia (14.00 mm), and Klebsiella pneumoniae (12.33 mm). The methanolic bark extract inhibited S. aureus $(24.33 \mathrm{~mm})$, P. aeruginosa $(10.66 \mathrm{~mm})$, E. coli $(11.33 \mathrm{~mm})$, A. serratia $(9.66 \mathrm{~mm})$, and K. pneumoniae $(11.66 \mathrm{~mm})$. Aqueous bark extract inhibited S. aureus $(22.33 \mathrm{~mm})$, P. aeruginosa $(8.33 \mathrm{~mm})$, E. coli $(9.33 \mathrm{~mm})$, A. serratiaa $(8.33 \mathrm{~mm})$, and K. pneumoniae $(9.66 \mathrm{~mm})$. Its aqueous extract showed the highest antioxidant potency; $\mathrm{IC}_{50}(0.175 \mu \mathrm{g} / \mathrm{mL})$ followed by the methanolic extract; $\mathrm{IC}_{50}(0.210 \mu \mathrm{g} / \mathrm{mL})$ and extract-loaded nanoparticles; $\mathrm{IC}_{50}(0.901 \mu \mathrm{g} / \mathrm{mL})$. Our findings provide meaningful interest for antioxidant, anti-microbial applications of, and AgNPs synthesis by, aqueous bark extract of $A$. indica.
\end{abstract}

Keywords: Aesculus indica; biogenic synthesis-AgNPs; antimicrobial; antioxidant; phytochemicals

\section{Introduction}

In this modern era, scientists have been devoted to exploring the optimum use of materials and/or resources available on the earth for the wellbeing of humans as well as the environment. This is further intensified because of the considerable damage that has already been made to the environment and ecosystems due to the over-use of various toxic materials in industrial processes. Fortunately, nanotechnology has evolved as an effective medium to combat many scientific and technical issues in all spheres of life. Particularly, nanotechnology has become of critical importance with applications ranging from industrial, optoelectronics, biological, and biomedical sciences. The greater surfaceto-volume ratio of nanomaterials phenomenally enhances their properties and activities. 
Thus, they are being extensively studied for diagnosis, drug-carriers, and potential drugs. In this connection, the scientific community has already explored numerous physical and chemical methods for the synthesis of various nanomaterials, which are the fundamental building blocks of nanotechnology. The notable methods can be identified as microwave digestion, laser ablation, photochemical reduction, ion sputtering, sol-gel, sonochemical, ultrasonic spark discharge, template synthesis, etc. [1-4]. It is worth mentioning that most of these physical, chemical, electrochemical, and photo-reduction methods show considerable drawbacks including the use of expensive and hazardous chemicals, consumption of huge energy, and generation of a large amount of toxic waste and pollutants as by-products. However, the biogenic and/or green synthesis of nanomaterials using plant extracts has evolved as an effective pathway to overcome the aforementioned drawbacks, because such methods do not use toxic chemicals and are economical as well. Specifically, for biomedical applications, nanomaterials prepared by plants extracts provide stability and safety due to the chelation of phytochemicals [5]. Among the notable metallic nanoparticles $(0.1-100 \mathrm{~nm})$ obtained via green synthesis, gold $(\mathrm{Au})$, silver $(\mathrm{Ag})$, platinum $(\mathrm{Pt})$, and palladium $(\mathrm{Pd})$ are of superior importance due to their better tolerance in biological systems. However, applications of metallic nanomaterials show some challenges due to their unwanted interactions with non-target proteins, fatty acids, and DNA. Silver and its nanoparticles have higher tolerance in biological systems and, thus, have centuries-old uses for treating infections. Nevertheless, regulating and minimizing off-target modulations are of critical research interest for developing safer biomedical products [5]. The influence of phytochemicals on the stability and biological safety of nanomaterials synthesized by plant extracts is of supreme importance because these phytochemicals chelate with nanomaterials, which enhances their stability, minimizes their off-target bindings, and neutralizes the generated free-radicals $[5,6]$. This scenario incredibly enhances the importance of biological synthesis of nanoparticles, and, also, these methods are inexpensive, applicable at a large scale, and non-toxic [5-7]. These biogenic methods use enzymes, microorganisms, and plants for the synthesis of nanoparticles. Moreover, the use of plants extract offers various advantages and ease of controlling parameters [8,9]. Medicinal plants are nature's gift to humans, which provide food, traditional herbal medicinal products (THMPs), and molecular medicines. Nature's design and novelty of natural products and their therapeutic applications are beyond imaginations and provide biologically active natural products such as drugs, drug candidates, and scientific imaginations. Plant-based natural products have provided the most important drugs and are still the most promising reservoirs for drug discovery. The richness and diversity of plants for natural molecules phenomenally empower them to reduce metals for green synthesis of nanoparticles and provide valuable advantages.

Aesculus indica (Family: Sapindaceae: Indian horse chestnut or Himalayan chest nut) is a big tree that habitats in the Himalaya Mountains ranging from Pakistan to Nepal. It is reported to possess a long range of biological properties including treating skin diseases, rheumatism, and headaches. Particularly, its seeds are astringent and the oil is used to treat skin diseases and rheumatism. Furthermore, its fruits are traditionally used for treating GITdisorders, whereas the roots are used to regulate the hormonal imbalance. It is also reported to possess anti-oxidant, anti-viral immune-modulatory, anti-inflammatory spasmolytic, and neuro-depressive activities $[10,11]$. Aesculus indica is reported to be rich and diverse in its natural products, containing terpenoids, saponins, long-chain fatty acids, and important phenolic natural products including flavonoids, their glycosides, coumarins, and tannins. These natural products are responsible for their biological properties and favored the biosynthesis of nanoparticles. Its famous constituent, aescin, is responsible for its toxic properties [12]. The worth of its various dietary and medicinal properties and uses is also evident by over 60 publications on this plant in 2020 alone [13]. Interestingly, leaves of Aesculus indica biosynthesize a higher quantity of quercetin, whereas its bark biosynthesizes its glycoside, rutin (and also astragalin; glycosidic apigenin). This is a highly exploitable finding that quercetin has higher anti-oxidant properties, and rutin has greater inhibition to arthritis, inflammations, and infections. Green synthesis of silver-nanomaterials using 
A. indica is aimed for having greater stability and less toxic AgNPs products because of the presence of major natural chelating agents $[12,14]$. The richness and diversity of $A$. indica for its natural products and biological properties prompted us to investigate its ability for nanoparticles synthesis and biological properties as well as phytochemical estimations of A. indica found in the Pakistani-Kashmir. According to the literature searches, this has not been reported earlier. Additionally, wide differences in the environmental and climatic conditions in its large habitat region make it important to study the properties of $A$. indica obtained from the Pakistani mountainous habitat.

\section{Experimental Details}

\subsection{Plant Material and Chemicals}

The bark of Aesculus indica was collected up from district Neelum of AJK, Pakistan, the authenticity was verified by an eminent plant scientist and Prof. Dr. Muhammad Q. Khan (Department of Plant Sciences, University of AJK), and the specimen was kept in the department. The bark was removed from fresh plants and the dried plant material was used for the preparation of extracts. Laboratory grade silver nitrate $\left(\mathrm{AgNO}_{3}\right)$, acetone, methanol, Wagner's reagent, ferric chloride, lead acetate, zinc powder, ninhydrin, Benedict's reagent, $\mathrm{H}_{2} \mathrm{SO}_{4}, \mathrm{HCl}, \mathrm{DPPH}$, ascorbic acid, and nutrient agar were purchased from Sigma-Aldrich.

\subsection{Preparation of Aqueous and Methanol Extracts}

The plant material was washed twice with distilled water (d-water) and then dried under shade for about 10 days, and, subsequently, the dried powder was ground using an electrical grinder. Water extract was prepared by $10 \mathrm{~min}$ heating of $20 \mathrm{~g}$ of this powder in $200 \mathrm{~mL}$ d-water using a $500 \mathrm{~mL}$ conical flask. Afterward, upon cooling to room temperature, it was filtered (Whatman paper No.1) and this extract was used for preparing AgNPs, phytochemical screening, and antioxidant and antibacterial activities.

An amount of $10 \mathrm{~g}$ of powdered bark was added to $100 \mathrm{~mL}$ methanol in a $250 \mathrm{~mL}$ Erlenmeyer flask. This solution was shaken for $24 \mathrm{~h}(200 \mathrm{rpm})$. Afterward, this was filtered, the solvent was evaporated to obtain crude extract and the resulting residue was stored in an airtight container $\left(4^{\circ} \mathrm{C}\right)$, which was then ready for phytochemical screening, and antibacterial and antioxidant activities.

\subsection{Biogenic Preparation of AgNPs}

Aqueous extract of the bark of $A$. indica $(100 \mathrm{~mL})$ was added with $100 \mathrm{~mL}$ aqueous solution of $5 \mathrm{mM}$ of $\mathrm{AgNO}_{3}$ in a $250 \mathrm{~mL}$ reaction flask. The mixture was kept in dark, and the reduction process occurred at room temperature. The reduction of Ag-ions was indicated by the change in color (from reddish-orange to dark brown). The confirmation of AgNPs synthesis was obtained by using UV-visible spectroscopy. Reduction of silver was completed by about $24 \mathrm{~h}$ of reaction, and then this mixture containing AgNPs was centrifuged for $5 \mathrm{~min}$ at a speed of 15,000 rpm in order to separate the AgNPs. Distilled water was used to wash the resulting precipitates, centrifuged, and then washed with acetone. The dried AgNPs were characterized by XRD, FT-IR, and SEM.

\subsection{Characterization of AgNPS}

\subsubsection{UV-Visible Spectroscopic Analysis}

The reduction progress of Ag (AgNPs-formation) was monitored by the UV-visible spectroscopic analysis periodically, at $0 \mathrm{~h}, 6 \mathrm{~h}, 12 \mathrm{~h}$, and $24 \mathrm{~h}$ using Analytik-Jena SPECORD $50 \mathrm{UV}-$ Vis Spectrometer.

\subsubsection{XRD Analysis}

The crystallographic structure and size of AgNPs were determined by X-Ray Diffraction Analysis using AgNPs-dried powder and Bruker D8 powder X-ray Diffractometer. 
The size of crystalline-nanoparticles was determined via the Debye Scherrer formula from the XRD peaks,

$$
D=\frac{k \lambda}{\beta \cos \theta}
$$

$D=$ average particle size,$k=$ particle shape factor $(0.89), \lambda=$ wavelength of the $\mathrm{X}$-ray beam used $(0.154 \mathrm{~nm}), \beta=$ full width at half-maximum (FWHM) of (1 111$)$ plane, and $\theta=$ Bragg's angle or diffraction angle in radian.

\subsubsection{SEM Analysis}

The morphology and distribution of AgNPs were observed using SEM (Jeol JSM6510LV). Samples were prepared by dispersing the Ag-nanoparticles on a stub that was covered with a carbon tap.

\subsubsection{FT-IR Analysis}

FTIR measurements were taken to identify the functional groups of natural products that played an important role in the reduction (formation of AgNPs) and stabilization of synthesized AgNPs. Dried powder of AgNPs was used for FTIR analysis using PerkinElmer Spectrum 100 FTIR Spectrometer.

\subsection{Qualitative Phytochemical Analysis}

Both aqueous and methanolic extracts (bark of $A$. indica) were analyzed for the detection of alkaloids, amino acids, phenols, saponins, flavonoids, tannins, glycosides, and polysaccharides according to the standard methods and reported procedures [15].

\subsubsection{Test for Alkaloids Estimation}

The presence of alkaloids was determined by treating methanolic and aqueous bark extract, in separate test tubes, by adding 3-5 drops of Wagner's reagent in each sample.

\subsubsection{Test for Saponins Estimation}

The presence of saponins was analyzed by gentle shaking of $0.5 \mathrm{~g}$ crude extract in $5 \mathrm{~mL}$ distilled water for $2 \mathrm{~min}$.

\subsubsection{Test for Tannins Estimation}

A Ferric chloride test was performed for the presence of tannins by adding a few drops of $\mathrm{FeCl}_{3}$ in $5 \mathrm{~mL}$ extract in a test tube.

\subsubsection{Test for Flavonoids Estimation}

Pew's Test was used to observe the presence of flavonoids, i.e., 2-3 mL extract in a test tube was added with a tiny amount of $\mathrm{Zn}$-powder and conc. $\mathrm{HCl}$ in a drop-wise manner.

\subsubsection{Test for Amino Acids Estimation}

The presence of amino acids and proteins was checked by adding a few drops of $5 \%$ ninhydrin solution into a $2-3 \mathrm{~mL}$ extract solution in a test tube.

\subsubsection{Test for Carbohydrates Estimation}

The presence of carbohydrates was identified via Benedict's test wherein, $500 \mathrm{mg}$ of crude extract was dissolved in $2 \mathrm{~mL}$ of Benedict's.

\subsubsection{Test for Phenols Estimation}

The presence of phenols was checked by dissolving $300 \mathrm{mg}$ crude extract in $5 \mathrm{~mL}$ distilled water then by adding 5 drops of $5 \% \mathrm{FeCl}_{3}$ solution. 


\subsubsection{Test for Cardiac Glycosides Estimation}

Keller Killiani's test: To observe the presence of cardiac glycosides, $0.5 \mathrm{~g}$ of crude bark extract, $0.4 \mathrm{~mL}$ glacial acetic acid, and a minute quantity of ferric chloride were mixed in a test tube and then $0.5 \mathrm{~mL}$ of conc. $\mathrm{H}_{2} \mathrm{SO}_{4}$ was added carefully to it by the side of a test tube.

\subsection{Biological Activity}

2.6.1. Microorganisms Collection and Preparation of Inoculums for Antibacterial Activities

Anti-bacterial activities of three different extracts and AgNPs were tested against five bacterial strains, i.e., Staphylococcus aureus, Escherichia coli, Pseudomonas aeruginosa, Klebsiella pneumoniae, and Acetobacter serratia. All these strains were collected from the CMH-Hospital, Muzaffarabad, AJK, Pakistan. Preparation of fresh bacterial cultures was carried out by streaking loop full of bacterial suspension to Petri plates provided with nutrient-agar medium and was incubated at $37^{\circ} \mathrm{C}$ to ensure the growth of the microorganism.

\subsubsection{Antibacterial Activities}

The antibacterial activities were conducted by using the Disc-diffusion method [16,17]. To prepare the Petri plates, one streaking loop full of bacterial suspension was dissolved into $2 \mathrm{~mL}$ of distilled water in a test tube followed by vertex mixing to completely dissolve the bacterial suspension. The $2 \mathrm{~mL}$ inoculum of each bacterial strain was poured into separate Petri plates. Then, $30 \mathrm{~mL}$ nutrient agar medium was poured into each plate and became solidified after a few minutes. Sterilized and air-dried filter paper discs (6 mm) were impregnated with samples to be tested, air dried, and planted on the solidified agar medium surface. Ampicillin discs were used as control. The bacterial Petri plates were incubated at $37^{\circ} \mathrm{C}$ for $24 \mathrm{~h}$. A measuring scale was used to record the inhibition of growth zones (diameter in $\mathrm{mm}$ ). The entire procedure of measuring the antibacterial activities of plant extract and AgNPs was carried out in triplicate. Inhibition zones of the growth of microorganisms of less than $12 \mathrm{~mm}$ (diameter) were considered as low antibacterial activity, 12 to $16 \mathrm{~mm}$ (diameters) as moderately active, and $>16 \mathrm{~mm}$ as extremely active.

\subsubsection{Antioxidant Activities}

Antioxidant activities of $A$. indica bark extract and synthesized AgNPs were determined by using DPPH radical scavenging assay [18]. To prepare the stock solution, $7 \mathrm{mg}$ of DPPH powder was added in a conical flask containing $100 \mathrm{~mL}$ methanol. DPPH solution along with methanol and bark extract with different concentrations $(10 \mu \mathrm{g} / \mathrm{mL}, 20 \mu \mathrm{g} / \mathrm{mL}$, and $30 \mu \mathrm{g} / \mathrm{mL}$ ) were transferred in labeled test tubes for sample reading, mixed properly, and incubated for about $30 \mathrm{~min}$. Ascorbic acid was used as standard. UV-visible absorbances were measured at $517 \mathrm{~nm}$ and percentage radical scavenging activity was measured thrice using the following formula.

$$
\% \text { Inhibition }=100 \times\left(\frac{A_{\text {control }}-A_{\text {test }}}{A_{\text {control }}}\right)
$$

where $A_{\text {test }}=$ absorbance of the test compound, $A_{\text {control }}=$ absorbance of ascorbic acid.

The MSTATC software was used to analyze the data. Measurements were taken in three replicates and the means were taken by using Duncan Multiple range tests [19]. $p$ values less than 0.05 were taken as being statistically significant. All experiments were performed in triplicates, and values were expressed as mean $\pm \mathrm{SD}$. Linear regression analysis among the percent inhibition of extracts, and MS-Excel 2007 was used to calculate $\mathrm{IC}_{50}$.

\section{Results and Discussion}

Upon mixing the aqueous $\mathrm{AgNO}_{3}$ solution with the aqueous bark extract of Aesculus indica, the reddish-orange color of the bark extract was changed into dark brown (Figure 1). This color change was the first indication of silver nanoparticles synthesis by bark extract. 
The initial color change took place almost after $15 \mathrm{~min}$. The phenomenon of Surface Plasmon Resonance (SPR) in AgNPs was found responsible for this color changes.

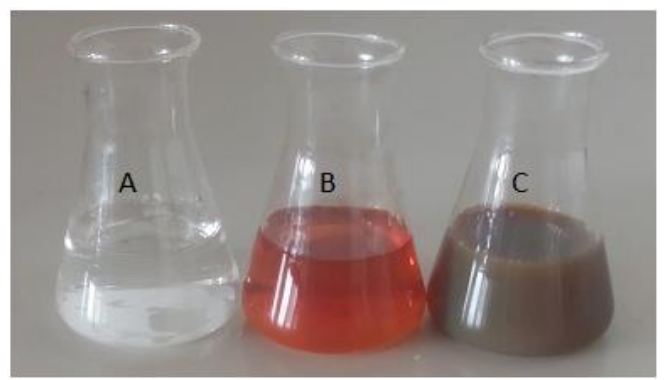

Figure 1. (A): Colorless solution of $\mathrm{AgNO}_{3}$ (B): After the addition of bark extract, orange color appeared (C): Orange color changed to dark grey, indicating the AgNPs formation.

The color change indicated the formation of AgNPs that was certified by UV-Visible absorption. For UV-Visible analysis, a small fraction of solution diluted with $5 \mathrm{~mL}$ distilled water was taken into a cuvette, whereas blank reading was taken by using distilled water as a reference. The wavelength range of the spectrophotometer was selected in the region of 300-800 nm for each sample. Bark extract of A. indica was used to reduce the silver and stabilize the resulting $\mathrm{AgNO}_{3}$. The UV-Visible spectroscopy showed active absorption at $461 \mathrm{~nm}$ because of Surface Plasmon Resonance in AgNPs after 15 min of exposure. With passing time, the peak was shifted towards the higher wavelength $(467 \mathrm{~nm})$, which is attributed to the increased size of AgNPs as time elapsed. Similarly, after $2 \mathrm{~h}$ the absorption band further enhanced, which showed more formation of AgNPs. Finally, after $24 \mathrm{~h}$, the peak was observed at about $471 \mathrm{~nm}$, which showed maximum reduction and completion of the AgNPs formation (Figure 2).

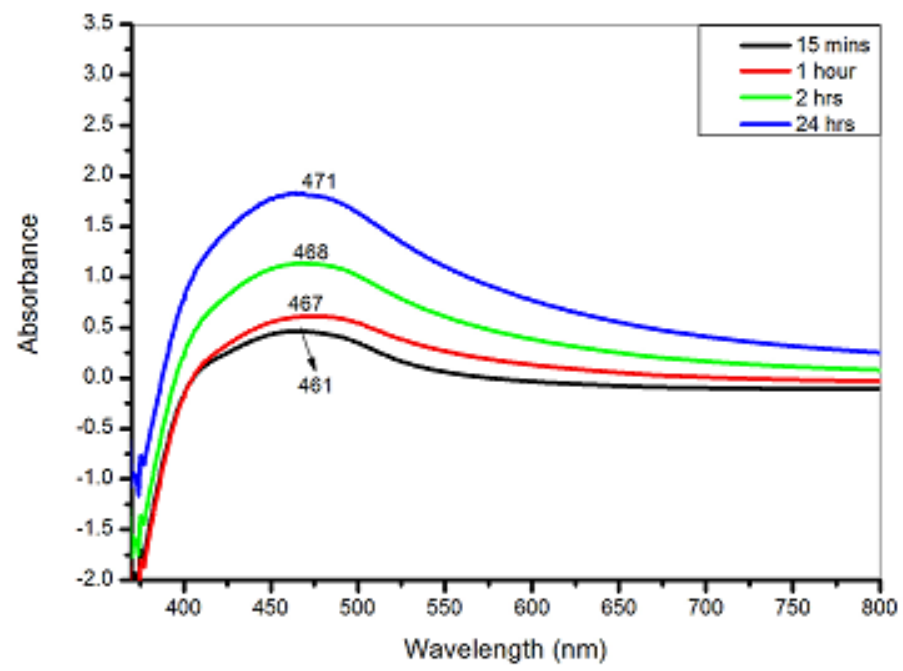

Figure 2. UV-Visible absorption of prepared AgNPs.

The XRD experiment confirmed the size and crystal nature of bio-synthesized AgNPs using the bark-extract of $A$. indica. The XRD analysis clearly showed that AgNPs synthesized by silver ions reduction by aqueous extract of the bark of $A$. indica possessed a crystalline nature (Figure 3). XRD pattern of these AgNPs showed various Bragg's reflections revealing the face-centered cubic structure because of excellent concurrence with the JCPDs (89-3722) standard card. The XRD analysis of AgNPs showed that the main diffraction peak centered at $2 \theta=38.12^{\circ}$, corresponding to the crystal plane with Miller indices (1 11 ), which is the characteristic peak for fcc structure. The average size of crystallite AgNPs was calculated applying the Debye Scherrer formula presented in Equation (1) on a high-intensity peak (111). 


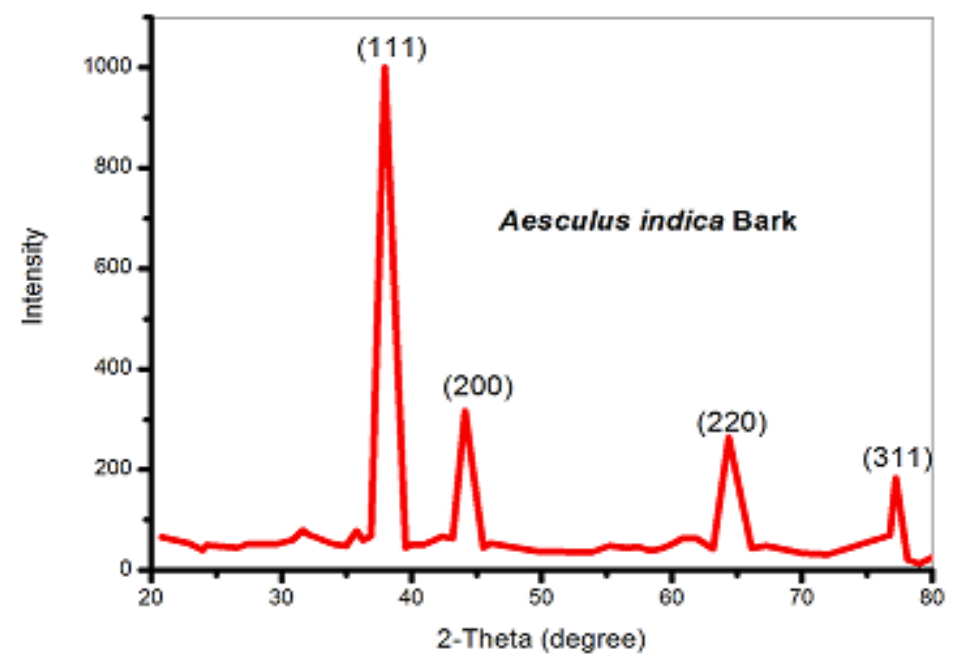

Figure 3. XRD Spectrum of AgNPs synthesized using bark's extract of Aesculus indica.

The calculated value of the average crystallite size of AgNPs $=42.96 \mathrm{~nm}$. The following Equation (3) was employed to calculate the average lattice constant that applies to the cubic system:

$$
\alpha=\lambda \frac{\sqrt{h^{2}+k^{2}+l^{2}}}{2 \sin \theta}
$$

For peak corresponding to (111) plane, the lattice constant is calculated to be ' $a$ ' $=4.085 \mathrm{~A}$. All values are precisely matched with the literature [20].

SEM (JEOL JSM-6490A Analytical Scanning Electron Microscope) was used to confirm the morphological characteristics of AgNPs (after $24 \mathrm{~h}$ of the reaction). The SEM images (Figure 4) showed the high intensity of AgNPs. It was also shown by the SEM that AgNPs were rod-shaped and with some of the irregular shapes of no defined morphology. Moreover, some NPs were dispersed and some were aggregated. These results matched with the reported results [20].

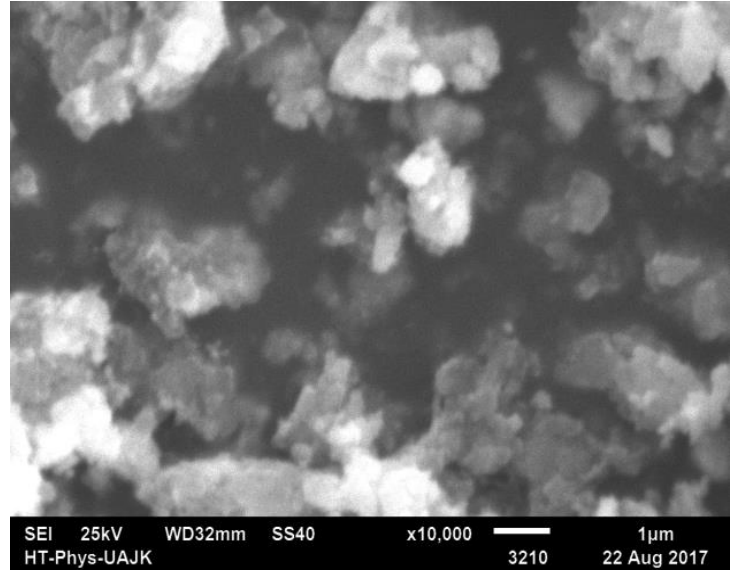

(A)

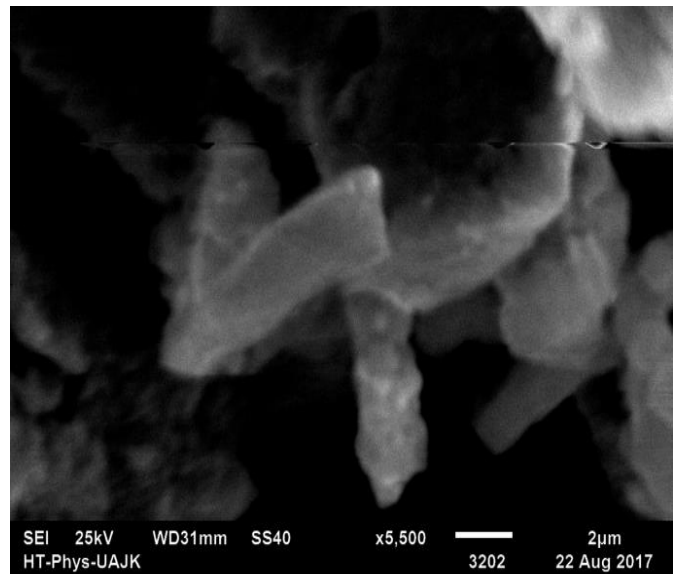

(B)

Figure 4. SEM images of AgNPs synthesized by Aesculus indica's bark extract. (A) High-resolution image. (B) Medium-resolution image.

The natural products present in $A$. indica (aqueous bark extract) showed sufficient potential for reducing the silver and stabilizing the resulting AgNPs, which were analyzed using FT-IR. A. indica bark-mediated AgNPs showed twelve absorption peaks in the FT-IR spectrum located at about 3397, 2944, 2478, 2013, 1559, 1419, 1105, 1070, 872, 814, 698, 
and $605 \mathrm{~cm}^{-1}$ (Figure 5). Among all these peaks, the band at $3397 \mathrm{~cm}^{-1}$ indicated $\mathrm{OH}$ group, and the band at $2944 \mathrm{~cm}^{-1}$ indicated the $\mathrm{C}-\mathrm{H}$ symmetric vibrations in saturated hydrocarbons. The strong absorption peaks at about 2013 and $1070 \mathrm{~cm}^{-1}$ indicated the $\mathrm{C}-\mathrm{N}$ group of amines. Two strong peaks at 1419 and $1559 \mathrm{~cm}^{-1}$ revealed the carbonyl $(C=O)$ functionalities. Intense absorption peaks at 872 and $814 \mathrm{~cm}^{-1}$ showed aromatic $C=C$ moieties. Sharp absorptions at 698 and $605 \mathrm{~cm}^{-1}$ were due to $C-X$ bonds of alkyl halides. FT-IR results also revealed that the indicated functional groups of phytochemicals, e.g., esters, amines, phenols, amides of proteins, and some conjugated compounds, played an important role in the biogenic synthesis of AgNPs (reducing and stabilizing). The obtained FT-IR results were in concordance with the literature reported elsewhere [20].

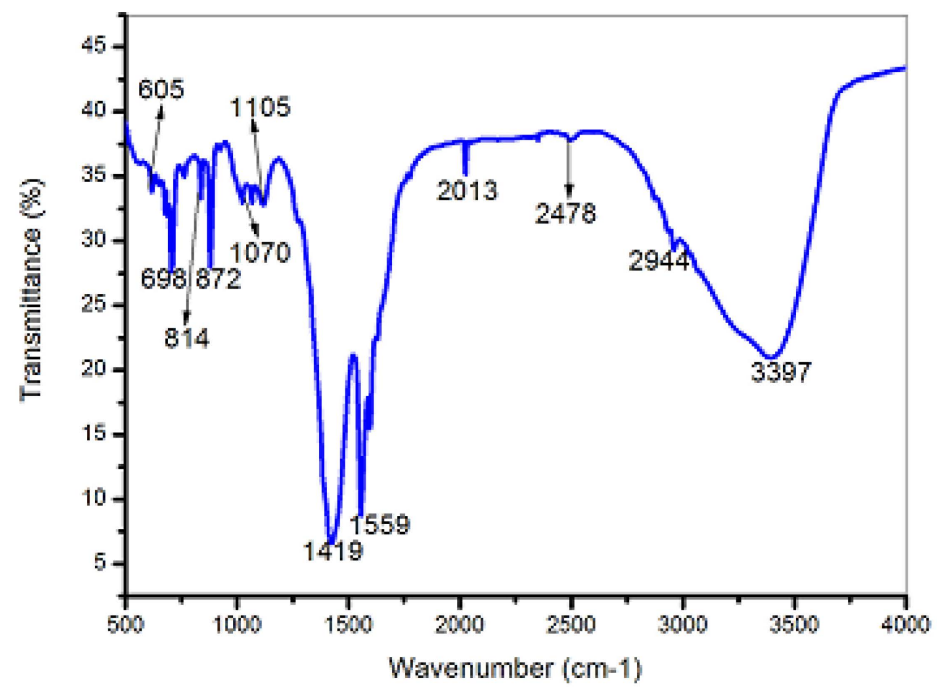

Figure 5. FT-IR spectrum of biosynthesized AgNPs using bark extract of $A$. indica.

Phytochemical screening of $A$. indica's bark showed the existence of flavonoids, tannins, carbohydrates saponins, and phenols in both aqueous and methanolic bark extract, whereas no traces of alkaloids, cardiac glycosides, and amino acids were detected in both extracts. The investigated phytochemicals are well known for their medicinal potentials [21].

Antibacterial screening of the $A$. indica bark extract showed significant activities against five bacterial strains (S. aureus, K. pneumonia, E. coli, P. auregenosa, and A. serratia). All the tested bacteria have shown significant sensitivity towards extracts and different concentrations of AgNPs. When the aqueous and methanol extracts of bark as well as AgNPs were tested against these bacteria, it was observed that the AgNPs ( $30 \mathrm{mg} / \mathrm{mL})$ showed the highest anti-bacterial activities (zone of inhibition $28.0 \mathrm{~mm}$ ) followed by AgNPs $(20 \mathrm{mg} / \mathrm{mL})$ with an inhibition zone $(26.33 \mathrm{~mm})$ against $S$. aureus. The lowest zone of inhibition $(8.33 \mathrm{~mm})$ of aqueous bark extract $(30 \mathrm{mg} / \mathrm{mL})$ was measured against both $P$. aeruginosa and $A$. serratia (Table 1 ). The present study revealed the increasing effect on microbial growth inhibition with increasing AgNPs concentration, and comparison with the literature showed the same results [22]. The AgNPs binding with the cell membrane and killing the bacterial cells has also been reported previously [22,23]. This might be due to the electrostatic attractions of a negatively charged bacterial cell membrane with a positive charge on the surface of AgNPs [23]. The present results support the previous studies on this species albeit from different habitats [14]. 
Table 1. Antibacterial activities of bark extract of Aesculus indica by Disc diffusion method.

\begin{tabular}{|c|c|c|c|c|c|c|}
\hline $\begin{array}{c}\text { Bacterial } \\
\text { Strains }\end{array}$ & $\begin{array}{c}\text { Aq. Extract } \\
30 \mathrm{mg} / \mathrm{mL}, \\
\text { Mean } \pm \text { SD } \\
(\mathrm{mm})\end{array}$ & $\begin{array}{c}\text { Methanol } \\
\text { Extract } \\
30 \mathrm{mg} / \mathrm{mL}, \\
\text { Mean } \pm \text { SD } \\
(\mathrm{mm})\end{array}$ & $\begin{array}{c}\text { AgNPs } \\
10 \mathrm{mg} / \mathrm{mL} \\
\text { Mean } \pm \text { SD } \\
(\mathrm{mm})\end{array}$ & $\begin{array}{c}\text { AgNPs } \\
20 \mathrm{mg} / \mathrm{mL} \\
\text { Mean } \pm \text { SD } \\
(\mathrm{mm})\end{array}$ & $\begin{array}{c}\text { AgNPs } \\
30 \mathrm{mg} / \mathrm{mL} \\
\text { Mean } \pm \text { SD } \\
(\mathrm{mm})\end{array}$ & $\begin{array}{c}\text { Control, } \\
\text { Mean } \pm \text { SD } \\
(\mathrm{mm})\end{array}$ \\
\hline E. coli & $9.33 \pm 0.57$ & $11.33 \pm 0.57$ & $12.33 \pm 0.57$ & $14 \pm 1$ & $14.33 \pm 1.52$ & $22.33 \pm 0.57$ \\
\hline P. aeruginosa & $8.33 \pm 0.57$ & $10.66 \pm 0.57$ & $11.66 \pm 1.52$ & $14.33 \pm 1.52$ & $17.66 \pm 1.15$ & $25 \pm 1$ \\
\hline S. aureus & $22.33 \pm 1.52$ & $24.33 \pm 1.52$ & $24.33 \pm 1.52$ & $26.33 \pm 1.52$ & $28 \pm 1.73$ & $31.66 \pm 2.51$ \\
\hline K. pneumoniae & $9.66 \pm 1.52$ & $11.66 \pm 1.52$ & $12 \pm 0.57$ & $13 \pm 1$ & $12.33 \pm 1.52$ & $16.66 \pm 0.57$ \\
\hline A. serratia & $8.33 \pm 0.57$ & $9.66 \pm 0.57$ & $11.33 \pm 1.15$ & $12.66 \pm 1.15$ & $14 \pm 1$ & $18.66 \pm 1.15$ \\
\hline
\end{tabular}

The antioxidant activities of methanolic extract, aqueous extract of the bark of A. indica, as well as biogenically synthesized AgNPs were carried out and compared. The antioxidant activities were calculated in terms of $\mathrm{IC}_{50}$ values for all samples. Among them (i.e., bark methanol extract, AgNPs, and aqueous extract), the aqueous extract showed the highest antioxidant activities $(0.175 \mu \mathrm{g} / \mathrm{mL})$, followed by methanol extract $(0.210 \mu \mathrm{g} / \mathrm{mL})$, and the minimum anti-oxidant activities were exhibited by the bark-mediated AgNPs $(0.901 \mu \mathrm{g} / \mathrm{mL})$ (Table 2). Moreover, these results revealed marginal enhancement in antioxidant activities of these AgNPs upon comparison with plant extracts. This indicates that the plant extracts were responsible for the majority of the anti-oxidant activities, whereas the contribution of AgNPs was not significant.

Table 2. Antioxidant activities of $A$. indica Bark extracts and synthesized AgNPs.

\begin{tabular}{ccccc}
\hline \multirow{2}{*}{ Extracts } & \multicolumn{3}{c}{ Percentage Scavenging Activity } & \multirow{2}{*}{ IC $_{\mathbf{5 0}}(\boldsymbol{\mu g} / \mathbf{m L})$} \\
\cline { 2 - 3 } & $\mathbf{1 0} \boldsymbol{\mu g} / \mathbf{m L}$ & $\mathbf{2 0} \boldsymbol{\mu g} / \mathbf{m L}$ & $\mathbf{3 0 ~} \mathbf{g} / \mathbf{m L}$ & \\
\hline Methanol & 15.29 & 35.07 & 33.97 & 0.210 \\
Aqueous & 44.96 & 68.04 & 37.27 & 0.175 \\
AgNPs & 14.19 & 61.44 & 86.72 & 0.901 \\
\hline
\end{tabular}

\section{Conclusions}

This study concludes that the efficient biogenic synthesis of AgNPs using bark's aqueous extract of $A$. indica provides a simple, eco-friendly, cost-effective, and reproducible method for preparing AgNPs. The synthesized AgNPs show fairly well-defined dimensions by reducing the silver ions, which makes this approach advantageous for the large-scale biosynthesis of nanomaterials. The verification of the synthesized AgNPs was performed by the absorption band of the UV-Visible spectrum at $461 \mathrm{~nm}$. Presumably, the presence of quercetin and rutin in the $A$. indica is responsible for the biogenic synthesis and stability of Ag-nanoparticles. The FT-IR study indicates the presence of functional groups as well as the phytochemicals that chelated to the AgNPs. The XRD provides the size of AgNPs as $42.96 \mathrm{~nm}$, whereas the SEM study revealed the rod shapes and irregular shapes of some AgNPs. The prepared AgNPs were found to be surrounded by a tiny layer of various natural products containing amines, aldehydes, ketones, alcohols, and acids functionalities. The higher contents of phenols and flavonoids along with nitrogenous natural products in this plant are rationally responsible for its effective free-radical capturing ability (anti-oxidant), which provides an opportunity for its being a potential target to tackle the oxidative stress due to the excessive free radicals [21]. Employing the known findings such as size, shape, higher stability, and minimized toxicity of Ag-nanomaterials are of fundamental importance for their effective and competitive biomedical applications. Technologically, these biogenic synthesized AgNPs can be used as an antiseptic agent in the wound-healing process. The observed anti-oxidant potentials revealed the scavenging of ROS, which together with the antimicrobial properties, resulted in the phytochemical-chelated AgNPs. Technically, this single-step biogenic synthesis approach provides substantial grounds to further investigate, 
and optimize the size, shape, stability, and safety of silver-nanomaterials using extracts from various parts $A$. indica. In light of this study, we propose that investigations of leaf and fruit extracts of $A$. indica may further improve the size of Ag-NPs (to lower than $20 \mathrm{~nm}$ ) and obtain a spherical shape, which will increase the antioxidant and antimicrobial potency, whereas improving the chelation of non-glycosidic flavonoids will enhance their ROS scavenging and safety.

Author Contributions: Conceptualization, M.R., A.S. and P.A.; methodology, M.R. and A.S.; software, M.R. and A.S.; validation, P.A., M.U.K. and A.A.; formal analysis, M.R., A.S. and P.A.; investigation, M.R., A.S., A.A. and P.A.; resources, M.R., A.A., M.Q.K. and P.A.; data curation, P.A.; writing-original draft preparation, M.R., A.S. and P.A.; writing-review and editing, M.R., A.A., P.A., D.A.B. and M.U.K.; visualization, M.R., A.S., P.A., M.Q.K. and A.A.; supervision, M.R.; project ad-ministration, M.R., A.A. and P.A.; funding acquisition, M.R., A.A. and M.U.K. All authors have read and agreed to the published version of the manuscript.

Funding: This research was funded by Deputy Deanship for Research \& Innovation, Ministry of Education, Saudi Arabia through the project number IFP-KKU-2020/4.

Data Availability Statement: All data are available in the manuscript.

Acknowledgments: Authors thank the Deputy Deanship for Research \& Innovation, Ministry of Education, Saudi Arabia for funding this research work through the project number IFP-KKU-2020/4.

Conflicts of Interest: The authors declare no conflict of interest.

\section{References}

1. Ahmad, P.; Khandaker, M.U.; Khan, Z.R.; Amin, Y.M. Synthesis of boron nitride nanotubes via chemical vapour deposition: A comprehensive review. RSC Adv. 2015, 5, 35116-35137. [CrossRef]

2. Akter, N.; Ayob, M.T.M.; Radiman, S.; Khandaker, M.U.; Osman, H.; Alamri, S. Bio-Surfactant Assisted Aqueous Exfoliation of High-Quality Few-Layered Graphene. Crystals 2021, 11, 944. [CrossRef]

3. Itas, Y.S.; Ndikilar, C.E.; Zangina, T.; Hafeez, H.Y.; Safana, A.; Khandaker, M.U.; Ahmad, P.; Abdullahi, I.; Olawumi, B.K.; Babaji, M.A.; et al. Synthesis of Thermally Stable h-BN-CNT Hetero-Structures via Microwave Heating of Ethylene under Nickel, Iron, and Silver Catalysts. Crystals 2021, 11, 1097. [CrossRef]

4. Roy, A.; Elzaki, A.; Tirth, V.; Kajoak, S.; Osman, H.; Algahtani, A.; Islam, S.; Faizo, N.L.; Khandaker, M.U.; Islam, M.N.; et al. Biological Synthesis of Nanocatalysts and Their Applications. Catalysts 2021, 11, 1494. [CrossRef]

5. Ahmad, S.; Munir, S.; Zeb, N.; Ullah, A.; Khan, B.; Ali, J.; Bilal, M.; Omer, M.; Alamzeb, M.; Salman, S.M.; et al. Green nanotechnology: A review on green synthesis of silver nanoparticles-An ecofriendly approach. Int. J. Nanomed. 2019, 14, 5087. [CrossRef]

6. Gupta, N.; Fischer, A.R.; Frewer, L.J. Ethics, Risk and Benefits Associated with Different Applications of Nanotechnology: A Comparison of Expert and Consumer Perceptions of Drivers of Societal Acceptance. NanoEthics 2015, 9, 93-108. [CrossRef] [PubMed]

7. Kehri, H.K.; Zoomi, I.; Singh, U.; Pandey, D.; Pandey, D. Review on Biogenic Synthesis of Nanoparticles and Their Therapeutic Applications: List of Novel Eco-Friendly Approaches. J. Nanosci. Technol. 2019, 5, 810-816. [CrossRef]

8. Makarov, V.; Love, A.; Sinitsyna, O.; Makarova, S.; Yaminsky, I.; Taliansky, M.; Kalinina, N.O. “Green” nanotechnologies: Synthesis of metal nanoparticles using plants. Acta Nat. 2014, 6, 35-44. [CrossRef]

9. Pal, D.; Singh, H.; Kumar, M.A. A preliminary study on the in vitro antioxidant activity of seeds of Aesculus indica and bark of Populus euphratica. Int. J. Pharm. Pharm. Sci. 2012, 4, 249-250.

10. Zhang, Z.; Li, S.; Lian, X.-Y. An Overview of Genus Aesculus L.: Ethnobotany, Phytochemistry, and Pharmacological Activities. Pharm. Crops 2010, 1, 24-51. [CrossRef]

11. Shafi, S.; Wani, I.A.; Gani, A.; Sharma, P.; Wani, H.M.; Masoodi, F.A.; Khan, A.A.; Hamdani, A.M. Effect of water and ether extraction on functional and antioxidant properties of Indian horse chestnut (Aesculus indica Colebr) flour. J. Food Meas. Charact. 2016, 10, 387-395. [CrossRef]

12. Kaur, L.; Joseph, L.; George, M.A. Phytochemical analysis of leaf extract of Aesculus indica. Int. J. Pharm. Pharm. Sci. 2011, 3, 232-234.

13. Riaz, M.; Altaf, M.; Ahmad, P.; Khandaker, M.U.; Osman, H.; Eed, E.M.; Shakir, Y. Biogenic Synthesis of Ag Nanoparticles of 18.27 $\mathrm{nm}$ by Zanthozylum armatum and Determination of Biological Potentials. Molecules 2022, 27, 1166. [CrossRef]

14. Choudhary, M.; Kaushik, N.; Jangra, A. Phytochemical and pharmacological study of Aesculus indica linn. Plant: An updated review. J. Ayurveda 2021, 15, 141. [CrossRef]

15. Amarowicz, R.; Pegg, R.; Rahimi-Moghaddam, P.; Barl, B.; Weil, J. Free-radical scavenging capacity and antioxidant activity of selected plant species from the Canadian prairies. Food Chem. 2004, 84, 551-562. [CrossRef] 
16. Steel, R.; Torrie, J.; Dickey, D. Principles and Procedures of Statistics, Approach; McGraw Hill Co.: New York, NY, USA, 1997; pp. 178-182.

17. Song, J.Y.; Kim, B.S. Rapid biological synthesis of silver nanoparticles using plant leaf extracts. Bioprocess Biosyst. Eng. 2009, 32, 79-84. [CrossRef]

18. Anandalakshmi, K.; Venugobal, J.; Ramasamy, V. Characterization of silver nanoparticles by green synthesis method using Pedalium murex leaf extract and their antibacterial activity. Appl. Nanosci. 2015, 6, 399-408. [CrossRef]

19. Tejamaya, M. Synthesis, Characterization, and Stability Test of Silver Nanoparticles in Ecotoxicology Media. Doctoral Dissertation, University of Birmingham, Birmingham, UK, 2014.

20. Gupta, N.; Verma, K.; Nalla, S.; Kulshreshtha, A.; Lall, R.; Prasad, S. Free Radicals as a Double-Edged Sword: The Cancer Preventive and Therapeutic Roles of Curcumin. Molecules 2020, 25, 5390. [CrossRef]

21. Bayer, A.; Kirby, W.; Sherris, J.; Turck, M.J. Antibiotic susceptibility testing by a standardized single disc method. Am. J. Clin. Pathol. 1966, 45, 493-496. [CrossRef]

22. García-Sánchez, A.; Miranda-Díaz, A.G.; Cardona-Muñoz, E.G.J.O.M.; Longevity, C. The role of oxidative stress in physiopathology and pharmacological treatment with pro-and antioxidant properties in chronic diseases. Oxid. Med. Cell. Longev. 2020, 2020, 2082145. [CrossRef]

23. Gherasim, O.; Puiu, R.A.; Bîrcă, A.C.; Burdușel, A.-C.; Grumezescu, A.M. An Updated Review on Silver Nanoparticles in Biomedicine. Nanomaterials 2020, 10, 2318. [CrossRef] [PubMed] 